\title{
A study on the medicinal value and distribution of climbers of Nattika, India.
}

\author{
Abhilash ES ${ }^{1}$, Sheeja P Parayil'1, AR Raju², Brijesh Sathian ${ }^{3}$ and Vinil Udayan ${ }^{4}$.
}

${ }^{1}$ Assistant Professor, P.G. Department of Botany, Sree Narayana College, Nattika, Thrissur, Kerala.

${ }^{2}$ Associate Professor, P.G. Department of Botany, Sree Narayana College, Nattika, Thrissur, Kerala.

${ }^{3}$ Assistant Professor, MCOMS, Pokhara, Nepal.

${ }^{4}$ U.G. Student, P.G. Department of Botany, Sree Narayana College, Nattika, Thrissur, Kerala.

\section{Original Article}

\section{Corresponding Author}

Dr. Abhilash ES

Assistant Professor, P.G. Department of Botany

Sree Narayana College

Nattika, Thrissur, India

Email: abhies@gmail.com

\section{Abstract}

Seventeen climber species were collected from Nattika which is highly medicinal in nature. Five Climber species represented with high density, five with medium density and seven with low density respectively. The wild areas of the Nattika harbor some of the rare species that are not seen in adjacent lands. This study throws light to the importance of conservation of wild areas and also suggests that peoples will be benefited by sustainable use of medicinal plants.

Key Words: Climbers, Medicinal plants, Density.

\section{Introduction}

Current levels of assessment puts our country's total count of flora at more than $\mathbf{4 0 0 0 0}$ species and that of fauna at more than 89000 species. This has fetched India a well deserved place in the top ranking mega diversity countries of the world. Nearly one third of the floral species of India are endemics. The current count of flowering plant species in India, estimated at 17500 represents approximately $7 \%$ of the global count (Ravikumar and Ved, 2000).

There are various kinds of plant present in our nature i.e., trees, parasites, climbing plants etc. Climber plant have weak stem so in order to reach sun light they climb up. Some support with some special organ. Creepers, on the other hand literally 'creep' along the soil surface and spread over a long distance.

Climbing plants use other plants or rocks and manmade structures for support. Released from the function of holding up the plant shoots, the stems possess little or no ability to bear any weight, but instead they are very flexible and have considerable tensile strength, meaning that stems have evolved characteristics to resist pulling and twisting.

A climbing habit has evolved independently in several plant families, using many different climbing methods. Some plants climb by twining their stems around a support (morning glories, ipomoea species) other climb by way of adventitious, clinging roots (Hedera species), with twining petioles (Clematis species), or using tendrils, which can be specialized shoots (Vitaceae), leaves (Bignoniaceae), or even inflorescences (passiflora). Species of Parthenocissus (Vitaceae) produce twining tendrils that are modified stems, but which also produce adhesive pads at the end that attach themselves quiet strongly to the support.

A liana or liane is a woody climber that generally has roots in woodland or forest floor but its leaver often full sun, blanketing canopies of trees, often many meters from the ground. Lianas are especially abundant in wet tropical forests, where the flexible woody stems assume many interesting hanging forms. But in the wet tropics, species may also be wrapped tightly around the tree limbs, appearing to constrict the host.

According to Richards, (1952), the moist forests in Southeast Asia are among the oldest types of forests in the world, being at least 30 million years old endowed with predominant assemblage of woody climbers known as 'Lianas' which trap sunlight in between canopies and play a vital role in functioning of this ecological system.

Apart from the aesthetic and ecological values, climbing plants are also medicinally important. Due to their multiple uses many climbers are recommended in ayurvedic tests for the treatment of various diseases.

A notable number of climber species which were predominant in our rural areas have been destroyed even from our rural areas due to various anthropogenic habitat destruction. Overwhelming of modern medicines has been distressing our human beings health considerably. Our indigenous knowledge of natural medicines from plants 
which are totally no side effects are to be explored and utilized for the well being of humans. Hence a study was undertaken to explore the climbers in and around areas adjoining to Nattika Coastal area.

\section{Material and Methods}

The study of the climbing plants was conducted in Nattika. The materials used and methods adopted in the study were according to Ravikumar and Ved (2000). The floristic exploration of climbers was carried out in Nattika Coastal area. Complete enumeration of the area with tagging the specimens was also conducted. A checklist of plants was made. The plants were assigned the status of H.D (High Density), M.D (Medium Density), and L.D (Low Density) according to their distribution density. The plant specimens collected were subjected to chemical treatment for killing and fixing and made herbarium accordingly.

Soil: - The soil of the experiment site was Coastal Alluvial Sandy.

Season: - The exploration was conducted during the January to March of 2012

\section{Results:}

The study revealed that five climbers are dominated in their distribution at Nattika area, they are Cayaratia mollisima, Cyclea peltata, Pothos scandense, Centrosema molle, Wattakaka volubilis (Table.1). Another five plants are sparsely distributed ie. Clitoria macrophylla, Hemidesmus indicus, Mukia scabrella, Passiflora edulis, Thunbergia fragrans (Table.1). Seven species are distributed/ represented rarely those include Abrus precatorius, Asparagus racemosus, Coccinia indica, Jacquemontia pentantha, Momordica charantia, Piper nigrum, Vigna anguiculata (Table.1).

Table.1 Density categorization of Climbers.

\begin{tabular}{|l|l|c|}
\hline Si No & Botanical Name & Density \\
\hline 1 & Abrus precatorius L & L.D \\
\hline 2 & Asparagus racemosus Willd & L.D \\
3 & Cayaratia mollissima, Gagn. & H.D \\
4 & Centrosema molle & H.D \\
5 & Clitoria macrophylla & M.D \\
6 & Coccinia indica & L.D \\
7 & Cyclea peltata (Lam) & H.D \\
8 & Hemidesmus indicus (L)R & M.D \\
9 & Jacquemontia pentantha & L.D \\
10 & Momordica charantia L & L.D \\
11 & Mukia scabrella L.f. & M.D \\
\hline 12 & Passiflora edulis & M.D \\
13 & Piper nigrum & L.D \\
14 & Pothos scandense Linn. & H.D \\
15 & Thunbergia fragrans roxb & M.D \\
16 & Vigna anguiculata & L.D \\
17 & Wattakaka volubilis & H.D \\
\hline
\end{tabular}

\section{Abrus precatorius $\mathrm{L}$}

Medicinal/ Economic Importance:

It possesses similar demulcent and emollient properties to those of the liquorice and to form an excellent substitute for it.

\section{Asparagus racemosus Willd}

\section{Medicinal/ Economic Importance:}

The tuberous roots are bitter, sweet, cooling, indigestible, appetizer, stomachic, tonic, aphrodisiac, galactogogue and astringent to the bowels. It is also useful in the treatment of tumors, inflammations, tuberculosis, leprosy, epilepsy, dysentery and night blindness. It is also used as a uterine sedative. Dried tuberous roots have ulcer healing resistance or cytoprotection. It has also been identified as one drug to control the symptoms of AIDS. Alcoholic extract of the roots increased the weight of mammary glands in post Partum \& estrogen- primedrats.

\section{Cayaratia mollissima Gagn.}

Medicinal/ Economic Importance:

The aerial parts or the roots are widely used for fever, and also to resolve toxins in mumps, jaundice and dysentery and disperse swellings in rheumatism. It act as a diuretic to treat haematuria. In decoction, the roots are applied for mastitis. Pounded leaves are put on scorpion stings and centipede bites. The ground root, together with black pepper (Piper nigrum L.), is applied to boils, as an astringent and disinfectant.

\section{Clitoria macrophylla}

Medicinal/ Economic Importance:Crude extract is used for treatment of skin diseases as well as in the treatment of inflammatory conditions..

\section{Coccinia indica W. \& A}

\section{Medicinal/ Economic Importance:}

Various preparations of roots, stems and leaves have been efficacious in the treatment of skin diseases, bronchitis and diabetics. Fruit juice powder showed anti-inflammatory and antinoiciceptive activities.

\section{Cyclea peltata (Lam)}

Medicinal/ Economic Importance:

Roots are reported to be useful in treating cough, bronchitis, diarrhoea, dysentery, dropsy, painful swellings, leprosy, skin diseases, ulcers, wounds, vomiting and cardiac disorders. The leaves are cooling and reported to be useful in dandruff, burning sensation of eye and fever. Tetrandrine isolated from this plant showed antitumor properties.

\section{Hemidesmus indicus (L) R}

\section{Medicinal/ Economic Importance:}

The dried roots are medicinal and constitute the Hemidesmus or Anantamed, which is official in Indian pharmacopoeia. Air dried roots are medicinal and used in traditional Ayurvedic 
medicine as a toxic, alternative, diaphoretic, blood purifier, in rheumatism and in skin infections. It is an important ingredient in more than 60 ayurvedic preparations. It is one of the ingredient in 'pindc taila' an ayurvedic drug. The roots are also used in nutritional disorder, syphilis, urinary disorder, skin burning, fissures in the feet and tooth ache. The roots stimulate lactation syrup from roots is used as a flavouring agent.

Methanolic extract of root bark showed antioxidant activity (Ravishankara et al.,2002) antithrombatic activity .

\section{Jacquemontia pentantha}

\section{Medicinal/ Economic Importance:}

The leaves and stems were used as a tonic for the treatment of weakness in babies.

The leaves and stems were applied externally to treat cuts. The dried leaves were chewed with coconut and the saliva swallowed for the treatment of catarrh (inflamed mucous membranes of the nose and throat).

\section{Momordica charantia L}

\section{Medicinal/ Economic Importance:}

It is used widely as a curative for constipation, diabetes, eczema, fat loss, food, fever, gout, hemorrhoids, hyperglycemia, increasing milk flow in feeding women, intestinal parasites, jaundice, kidney stones, liver, menstrual disorders, psoriasis, rheumatism, scabies etc

\section{Mukia scabrella L.f.}

\section{Medicinal/ Economic Importance:}

The plant has expectorant properties and is prescribed against chronic diseases with cough as a predominant symptom. The root of the plant, when masticated, relives toothache, a decocliori of the root is given in flatulence. The tender shoots and bitter leaves are used as a gentle aperients and prescribed in vertiligo and biliousness. A decoction of seed is considered sudorific.

\section{Passiflora edulis}

Medicinal/ Economic Importance:

It is used to treat nervous disorders, bronchial conditions, arthritis, asthma, insomnia, gastrointestinal disorders and menopausal symptoms. Fruit juice given to patients to induce sleep and leaf extract for the treatment of diabetes.

\section{Piper nigrum Linn.}

\section{Medicinal/ Economic Importance:}

It is used in treating digestive disorders, to eradicate parasitic worms and as an appetite stimulant, and to treat coughs, colds, breathing, heart problems, dyspepsia, cholera, syphilis, diabetes, anemia, sore throat and piles.

Black pepper decoction is gargled for tooth-ache, the paste is applied externally for healing boils and hair loss, mixed with sesame oil and applied for paralysis.

\section{Pothos scandense Linn.}

Medicinal/ Economic Importance:

The bruised root of the plant is applied to promote healing of abscesses, after being fried in oil. The boiled water with leaf is used after cooling bath for curing epilepsy.

\section{Wattakaka volubilis}

\section{Medicinal/ Economic Importance:}

Used to treat ailments such as obsesses, fever, rheumatism, sprue, asthma, sores, tooth ache, ear ache, snake bite etc. Plant is used in the treatment of cold and eye diseases. Leaves are applied to boils.

\section{Discussion:}

The occurrence of seventeen climber species at a small place shows the diverse nature of flora in the said area. The rich and diverse vegetation wealth of India is undoubtedly due to the varying climatic and geographical conditions and ecological habitats that exist in the country. Five climber species are dominated in their distribution at Nattika coastal area which includes Cayaratia mollisima, Cyclea peltata, Pothos scandense, Centrosema molle, Wattakaka volubilis due to their high ecological amplitude. Since they showed high density at unit area, they were categorized as H. D (High Density) species. On the other hand five plants are distributed with medium density ie. Clitoria macrophylla, Hemidesmus indicus, Mukia scabrella, Passiflora edulis, Thunbergia fragrans. So they are designated as M.D (Medium Density) species. Seven species are represented with very few number those include Abrus precatorius, Asparagus racemosus, Coccinia indica, Jacquemontia pentantha, Momordica charantia, Piper nigrum, Vigna anguiculata. They are given the status of L.D (Low Density) climber species but majority of them medicinally very important. Some of the climber species rarely represented in the said area in wild (Piper nigrum Hemidesmus indicus etc.) are vanished from our nearby agriculture lands. So wild areas could be the last resort of some plants in future years. The seventeen climber species with high medicinal properties shows their importance to the mankind. This study throws light to the importance of conservation of wild areas and also suggests that peoples will be benefited by sustainable use of medicinal plants.

\section{Conclusion:}

Seventeen climber species were collected from Nattika which is highly medicinal in nature. Five Climber species represented with high density, five with medium density and seven with low density respectively. The wild areas of the Nattika harbor some of the rare species that are not seen in adjacent lands.

\section{Acknowledgments:}

We are grateful to Dr. A.R.Raju, Head of the Department, S.N. College, Nattika for his valuable suggestions. We are extremely thankful for Dr. C.T. Anitha, Assistant Professor, Dept of Botany and Dr. P.Sujanapal, Scientist, KFRI for identifying difficult specimens. 


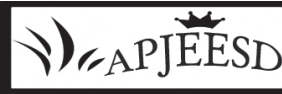

A study on the medicinal value and distribution of climbers of Nattika, India.

References:

Ravikumar, K and D.K. Ved. 100 Red listed Medicicinal Plants of conservation concern in Southern India. FRLHT, Banglore. $467 p$.

Richards, P.W. 1952. The Tropical Rain Forest. Cambridge University Press. 450p

\section{Article Information}

Article history

Received

Received in revised form

Accepted
18 October 2012

16 November 2012

2 December 2012 